\title{
Adverbs of Quantification and Sequence-of-Tense Phenomena
}

\author{
Toshiyuki Ogihara \\ University of Washington
}

\section{Introduction}

This paper discusses how tense morphemes and so-called adverbs of quantification such as always and often interact. In particular, I will pay attention to the relationship between temporal adverbial clauses and adverbs of quantification. I proposed in my earlier work (Ogihara 1989, ms.) that English (but not Japanese) has an optional syntactic rule that serves to delete tenses under identity with locally c-commanding tenses. Let us refer to the rule as the sequence-of-tense (SOT) rule. Regarding the interpretation of tenses, I argued that their relative structural positions at LF indicate the scope relationships among them. For example, if tense A locally c-commands tense B at LF, then B is in the scope of $A$. To be more precise, the semantic contribution of $B$ is determined in relation to the time of the episode that is described by the clause in which $A$ occurs. I made these claims based on the behavior of tenses in verb complement clauses and relative clauses. I will propose in this paper that these claims extend to temporal adverbial clauses. With regard to the interaction between tenses and adverbs of quantification (e.g., always), I will claim that matrix clause tenses have scope over quantificational adverbs.

In the tradition of formal semantics, past tense was assumed to induce existential quantification over past times (Prior 1967, Montague 1973, Needham 1975, Dowty 1979, Stump 1985, among others). Let us refer to this type of analysis as a quantificational theory of tense. Prior and Montague adopt sentential operators to symbolize tense morphemes, whereas Needham, Dowty and Stump employ a variant of intensional logic that uses constants and variables for times in the object language along with those for "normal" individuals. I will adopt the latter notation because of its flexibility. ${ }^{1}$ For example, (1a) is symbolized as (1b) in this notation:
(1) a. John died.
b. $\exists \mathrm{t}\left[\mathrm{t}<\mathrm{s}^{*} \&\right.$ John dies at $\left.\mathrm{t}\right]$

$s^{*}$ is an indexical constant that denotes the speech time. Thus, $t<s^{*}$ reads 't precedes the speech time.' A formula is informally symbolized as an English sentence in the present tense that occurs with a phrase of the form at $t$, which indicates the time at which the sentence is true. 2 The quantificational theory of tense has been challenged by various researchers. Partee (1973), among others, claims that at least in some cases, past tense simply functions like a free time variable whose value is fixed by the context of use. In this analysis, no existential quantification over times is invoked in the interpretation of past tense. This approach is referred to as a referential theory of tense. I claimed in my earlier work cited above that a quantificational analysis of tenses coupled with a contextual restriction upon its quantificational force is the best theory available. I will assume this theory throughout the paper. However, the proposal that I will make in this paper is independent of this controversy and can also be stated within a framework that espouses a referential theory of tense. 


\section{Tenses in Verb Complements and Relative Clauses}

Let me give a summary of my proposal made in Ogihara $(1989, \mathrm{~ms}$.), which accounts for the so-called sequence-of-tense phenomena in English and the lack thereof in Japanese. In English (2a) is optionally tumed into its LF structure (2b), whereas in Japanese the S-structure (2c) is identical to its LF structure, as far as tense morphemes are concerned:

(2) a. John said that Mary was sick. [S-structure]

b. John said that Mary $\varnothing$ be sick. [LF-structure]

c. Taroo-wa Hanako-ga byooki-da to iu -ta. [S-str. and LF]

TOP NOM be-sick PRES that say PAST

'Taroo said that Mary was sick.' [a simultaneous reading only]

When tense A locally c-commands tense B and A and B are occurrences of the same tense (i.e., PRES or PAST), the SOT rule optionally deletes B. The symbol " $\varnothing$ " in (2a) indicates a null tense node, which results from the application of the SOT rule. Both (2b) and (2c) translate as the following logical formula in the system I assume for the purpose of this paper:

\section{(3) $\exists \mathrm{t}\left[\mathrm{t}<\mathrm{s}^{*} \&\right.$ say' (t, j, ^ $\lambda \mathrm{t}^{\prime}$ [Mary is sick at $\left.\left.\left.\mathrm{t}^{\prime}\right]\right)\right]$}

In this notational system, the symbol " $\wedge$ " indicates worlds, not world-time pairs. Thus, any expression of the form $\wedge \lambda t \phi$, where $t$ is a time variable and $\phi$ a formula, denotes a proposition (i.e., a set of world-time pairs). In (3), $\wedge \lambda t^{\prime}$ [Mary is sick at $\left.t^{\prime}\right]$ denotes $\{\langle w, t\rangle \mid$ Mary is sick in $w$ at $t\}$. To obtain the desired interpretations for sentences that involve verb complement clauses, I assume a variant of Hintikka's proposal for propositional attitude verbs (Hintikka 1969): 【say' $\rrbracket_{\mathrm{w}}(\mathrm{p})(\mathrm{e})(\mathrm{t})$ (where $\mathrm{p}$ is a proposition, $e$ is an individual, and $t$ is an interval) $=$ 1 iff $\{<w ", t ">\mid<w ", t ">$ is compatible with what $e$ verbally expresses in $w$ at $t\}$ is a subset of $\left\{\left\langle w^{\prime}, t^{\prime}\right\rangle \mid p\left(w^{\prime}\right)\left(t^{\prime}\right)=1\right\}$. If $(2 b)($ or $(2 c))$ is true and if John speaks the truth when he said what he said, this can be interpreted as meaning that the pair consisting of the actual world and the time of John's saying is compatible with what John verbally expresses in the actual world at the time of his saying. Thus, if the sentence is true and John speaks the truth, Mary is sick at the time of John's saying. This correctly describes native speakers' intuition about $(2 \mathrm{~b}-\mathrm{c})$. This shows that the temporal location of the event or state described in the verb complement is determined in relation to the matrix clause episode, albeit indirectly.

Tenses in relative clauses receive approximately the same account. My proposal is quite simple. I accept the assumption that NPs are scope-sensitive expressions. NPs are generally known to exhibit scope properties with respect to each other. This is captured in many ways, but one common method is to allow NPs to move to S-adjoined positions at LF (called Quantifier Raising) so that scopally different readings for them result from various LF configurations (May 1977). I accept this proposal. Moreover, I propose that the SOT rule applies to tenses after $Q R$ does. The syntactic positions of tenses that result from $Q R$ and tense deletion determine the scope properties of tense morphemes. Depending upon whether a relative clause is scoped to a position higher than the matrix clause tense, the tense in the relative clause may or may not be caught by the matrix tense. If the relative clause tense remains in the scope of the matrix clause 
tense, it may be deleted by the SOT rule. We thus predict two or three temporal interpretations for any given relative clause. Let us consider some examples:

(4) a. At the airport, John will meet a man who is holding a book in his hand.

b. Taroo-wa [kodomo-no yooni nai-te ir -u otoko] ni au -ta. TOP child as if cry PROG PRES man DAT meet PAST 'John met a man who was crying like a baby (at the time).'

[a simultaneous reading (= a narrow scope reading for the NP)] 'John met a man who is now crying like a baby [over there].' [an "independent" reading (= a wide scope reading for the NP)]

(4a) shows that English tenses are sensitive to scope relations. It is ambiguous between the interpretation in which the time of the man's holding a book is the speech time and the one in which this time is simultaneous with the time of their meeting. These two interpretations are predicted by my proposal:

(5) a. $\exists x$ [ $x$ is a man at $\mathrm{s}^{*} \& \mathrm{x}$ is holding a book at $\mathrm{s}^{*} \&$

$\exists \mathrm{t}^{\prime}\left[\mathrm{s}^{*}<\mathrm{t}^{\prime} \&\right.$ John meets $\mathrm{x}$ at $\left.\left.\mathrm{t}^{\prime}\right]\right]$

b. $\exists \mathrm{t}^{\prime} \exists \mathrm{x}\left[\mathrm{s}^{*}<\mathrm{t}^{\prime} \&\right.$ John meets $\mathrm{x}$ at $\mathrm{t}^{\prime} \&$ $\mathrm{x}$ is a man at $\mathrm{t}^{\prime} \& \mathrm{x}$ is holding a book at $\left.\mathrm{t}^{\prime}\right]$

(5a) represents an "independent" reading associated with the wide scope NP, and (5b) a simultaneous reading associated with the narrow scope NP. Following Abusch (1988), I assume that will is morphologically analyzed into the present tense morpheme and the future auxiliary woll. Thus, the present tense morpheme in the relative clause is deleted under identity with the present tense in the matrix clause, and (5b) results. ${ }^{3}$ We shall see later that this fact can be used to argue against Stump's proposal that the present tense in English can have a non-past interpretation.

More decisive data come from Japanese. The Japanese sentence (4b) is ambiguous between the two interpretations indicated by the English glosses. ${ }^{4} \mathrm{My}$ proposal accounts for its ambiguity. A simultaneous reading results when the present tense in the relative clause is interpreted in situ (i.e., in the scope of the matrix tense), whereas an "independent" reading results when the relativized NP is scoped to a position outside the matrix tense. The two distinct readings associated with (4b) are symbolized as (6a) and (6b):

(6) a. $\exists \mathrm{t}^{\prime} \exists \mathrm{x}$ [t' $\mathrm{t}^{\prime}<\mathrm{s}^{*} \&$ John meets $\mathrm{x}$ at $\mathrm{t}^{\prime} \& \mathrm{x}$ is a man at $\mathrm{t}^{\prime} \& \mathrm{x}$ is crying at $\left.\mathrm{t}^{\prime}\right]$

b. $\exists x\left[x\right.$ is a man at $s^{*} \& x$ is crying at $s^{*} \&$ $\exists \mathrm{t}^{\prime}\left[\mathrm{t}^{\prime}<\mathrm{s}^{*} \&\right.$ Taroo meets $\mathrm{x}$ at $\left.\left.\mathrm{t}^{\prime}\right]\right]$

The proposed analysis predicts that (7a) is three ways ambiguous, as indicated by the translations $(7 \mathrm{~b}-\mathrm{d})$ : 
(7) a. John met a man who was crying like a baby.

b. $\exists t^{\prime} \exists x\left[t^{\prime}<s^{*} \&\right.$ John meets $x$ at $t^{\prime} \& x$ is a man at $t^{\prime} \& x$ is crying at $\left.t^{\prime}\right]$

c. $\exists \mathrm{t}^{\prime} \exists \mathrm{x}\left[\mathrm{t}^{\prime}<\mathrm{s}^{*} \&\right.$ John meets $\mathrm{x}$ at $\mathrm{t}^{\prime} \& \mathrm{x}$ is a man at $\mathrm{t}^{\prime} \&$ $\exists \mathrm{t}\left[\mathrm{t}<\mathrm{t}^{\prime} \& \mathrm{x}\right.$ is crying at $\left.\left.\mathrm{t}\right]\right]$

d. $\exists \mathrm{x}\left[\mathrm{x}\right.$ is a man at $\mathrm{s}^{*} \& \exists \mathrm{t}\left[\mathrm{t}<\mathrm{s}^{*} \& \mathrm{x}\right.$ is crying at $\left.\left.\mathrm{t}\right]\right] \&$ $\exists \mathrm{t}^{\prime}\left[\mathrm{t}^{\prime}<\mathrm{s}^{*} \&\right.$ John meets $\mathrm{x}$ at $\left.\mathrm{t}^{\prime}\right]$

The relativized NP in situ produces two interpretations. When the SOT rule deletes the tense in the relative clause, we obtain a simultaneous interpretation as in (7b). If the SOT rule does not apply, we obtain a shifted reading as in (7c), in which the time of the man's crying is located in the past of the meeting. (7d) results from the wide scope NP and predicts that the time of the man's crying can be any past time. I contend that although the three readings ( $7 b-d)$ do exist, the ambiguity is not detected because (7b-c) almost entail (7d). 5 Thus, extending my proposal to relative clauses is empirically motivated by the Japanese and English data.

\section{Temporal Adverbial Clauses with no Quantificational Adverbs}

The primary purpose of this paper is to study the interaction between temporal adverbial clauses and adverbs of quantification. As a preliminary, let us examine the behavior of temporal adverbial clauses in those examples that do not contain a quantificational adverb. Consider (8):

(8) John visited the Space Needle after he arrived in Seattle.

Let us take Stump's (1985) proposal as our starting point. Stump translates each clause as a temporal abstract (i.e., an expression of the form $\lambda t[\ldots t \ldots]$, which denotes a set of times). A temporal connective combines with a tensed clause to yield a temporal adverbial clause, which translates as yet another temporal abstract. It is then promoted to a generalized quantifier of times so that it can combine with the translation of the matrix clause. 6 The translation of $(8)$ is given in (9):

(9) 1. after $\Rightarrow \lambda P_{t} \lambda t^{\prime} \exists t\left[t<t^{\prime} \& P_{t}(t)\right]$

2. after he arrived in Seattle $\Rightarrow$ $\left.\lambda P_{t} \lambda t^{\prime} \exists t\left[t<t^{\prime} \& P_{t}(t)\right]\right]\left(\lambda t_{1}\right.$ [he arrives in Seattle at $\left.\left.t_{1} \& t_{1}<s^{*}\right]\right)$

3. $\lambda \mathrm{t}^{\prime} \exists \mathrm{t}\left[\mathrm{t}<\mathrm{t}^{\prime} \&\right.$ he arrives in Seattle at $\left.\mathrm{t} \& \mathrm{t}<\mathrm{s}^{*}\right]$

4. [promotion to a generalized quantifier of times] $\lambda Q_{t} \lambda t^{\prime}\left[\exists t\left[t<t^{\prime} \&\right.\right.$ he arrives in Seattle at $\left.\left.t \& t<s^{*}\right] \& Q_{t}\left(t^{\prime}\right)\right]$

5. John visited the Space Needle after he arrived in Seattle $\Rightarrow$ $\lambda Q_{t} \lambda t^{\prime}\left[\exists t\left[t<t^{\prime} \&\right.\right.$ he arrives in Seattle at $\left.\left.t \& t<s^{*}\right] \& Q_{t}\left(t^{\prime}\right)\right]$ $\left(\lambda \mathrm{t}_{1}\right.$ [John visits the Space Needle at $\left.\mathrm{t}_{1} \& \mathrm{t}_{1}<\mathrm{s}^{*}\right]$ )

6. $\lambda \mathrm{t}^{\prime}\left[\exists \mathrm{t}\left[\mathrm{t}<\mathrm{t}^{\prime} \&\right.\right.$ he arrives in Seattle at $\left.\mathrm{t} \& \mathrm{t}<\mathrm{s}^{*}\right]$ \& John visits the Space Needle at $\left.t^{\prime} \& t^{\prime}<s^{*}\right]$

7. [existential closure for the matrix clause] $\exists \mathrm{t}^{\prime}\left[\exists \mathrm{t}\left[\mathrm{t}<\mathrm{t}^{\prime} \&\right.\right.$ he arrives in Seattle at $\left.\mathrm{t} \& \mathrm{t}<\mathrm{s}^{*}\right] \&$ John visits the Space Needle at $\left.\mathrm{t}^{\prime} \& \mathrm{t}^{\prime}<\mathrm{s}^{*}\right]$ 
The last line says that John arrives in Seattle at some past time $t$, John visits the Space Needle at some past time $t$ ', and t' follows $t$. One important characteristic of Stump's proposal is that each tense morpheme is interpreted in relation to the speech time. The order of the two events is specified by the temporal connective after. The same proposal accounts for the interpretation of $(10 \mathrm{a})$, which involves before:

(10) a. John called Mary before he visited her.

b. $\exists \mathrm{t}\left[\mathrm{t}<\mathrm{s}^{*} \&\right.$ John calls Mary at $\mathrm{t} \& \exists \mathrm{t}^{\prime}\left[\mathrm{t}<\mathrm{t}^{\prime} \& \mathrm{t}^{\prime}<\mathrm{s}^{*} \&\right.$ John visits Mary at $\left.\left.t^{\prime}\right]\right]$

(10b) correctly describes the interpretation associated with (10a).

This approach faces difficulties when the main clause is in the future tense. Consider (11a) and (11b):

(11) a. John will call Mary after he finishes his assignment.

b. John will call Mary before he finishes his assignment.

Note that in (11a-b), the semantic contribution of the present tense in the adverbial clause cannot be measured relative to the speech time. If we assumed that a sentence in the present tense describes an episode that obtains at the speech time, we would predict that (11a-b) translate as (12a-b), respectively:

(12) a. $\exists t$ [he finishes his assignment at $s^{*} \& s^{*}<t \&$ John calls Mary at $\left.t\right]$

b. $\exists \mathrm{t}$ [he finishes his assignment at $\mathrm{s}^{*} \&$ $\mathrm{s}^{*}<\mathrm{t} \&$ John calls Mary at $\left.\mathrm{t} \& \mathrm{t}<\mathrm{s}^{*}\right]$

(12a-b) force the time of John's finishing his assignment to be the speech time, which is against native speakers' intuitions. (12b) even predicts that (11b) is never true because there is no time that both precedes and follows the speech time. Stump (1985) avoids this undesirable consequence by assuming that the present tense in English is ambiguous between a speech-time-oriented meaning and a non-past meaning. Following Stump's proposal, we predict that the translation of (11a) proceeds as in (13):

(13) 1. he finishes his assignment $\Rightarrow$ $\lambda_{\mathrm{t}}$ [he finishes his assignment at $\mathrm{t} \& \mathrm{~s} * \mathrm{t}$ ]

2. John will call Mary after he finishes his assignment $\Rightarrow$ $\exists \mathrm{t}\left[\mathrm{s}^{*}<\mathrm{t} \&\right.$ John calls Mary at $\mathrm{t} \& \exists \mathrm{t}^{\prime}\left[\mathrm{t}^{\prime}<\mathrm{t} \&\right.$ \& he finishes his assignment at $\left.\left.t^{\prime} \& s^{*} \leq t^{\prime}\right]\right]$

(13) makes roughly the right prediction. However, this analysis has a minor empirical problem: it allows the time of John's finishing his assignment to be the speech time. This does not agree with native speakers' judgments. Moreover, we cannot account for the fact that the adverbial clause cannot be in the future tense, instead of in the present tense: 7

(14) *John will call Mary when he will finish his book.

Since Stump assumes that tense morphemes in general specify their semantic 
contribution in relation to the speech time, there is no principled way of ruling out this possibility.

Furthermore, Stump's claim runs counter to the relative clause data discussed above. If we assume with Stump that a present tense morpheme in English can have a non-past interpretation, we predict among others the following interpretation for $(4 a)$ :

(15) $\exists \mathrm{x}$ [x is a man at $\mathrm{s}^{*} \& \exists \mathrm{t}^{\prime}\left[\mathrm{s}^{*} \leq \mathrm{t}^{\prime} \& \mathrm{x}\right.$ is holding a book at $\mathrm{t}^{\prime} \&$ $\exists \mathrm{t}\left[\mathrm{s}^{*}<\mathrm{t} \&\right.$ John meets $\mathrm{x}$ at $\left.\left.\left.\mathrm{t}\right]\right]\right]$

This means that the time of the man's holding a book can be any non-past time. This claim is not warranted. As mentioned above, the sentence has only two interpretations, and the time of the man's holding a book cannot be any non-past time.

Stump's proposal is particularly vulnerable to the following Japanese data, which have been discussed by Ota (1973), Nakau (1976) and Ogihara (1987): 8

(16) a. Taroo-wa Hanako-ni au mae -ni denwa-o si-ta. TOP DAT meet-PRES before at phone ACC do PAST 'Taroo called Hanako before he met her.'

b. Taroo-wa Hanako-ni au -ta -ato -ni denwa-o si-ta. TOP DAT meet PAST after at phone ACC do PAST 'Taroo called Hanako after he met her.'

c. Taroo-wa Hanako-ni au -mae -ni denwa-o su-ru. TOP DAT meet-PRES before at phone ACC do PRES 'Taroo will call Hanako before he meets her.'

d. Taroo-wa Hanako-ni au -ta -ato -ni denwa-o su-ru. TOP DAT meet PAST after at phone ACC do PRES 'Taroo will call Hanako after he meets her.'

e. Taroo-wa kanasii toki kokyoo -o omoidasi -ta. TOP be-sad-PRES when home-town ACC remember PAST 'Taroo remembered his home town when he was sad.'

f. Taroo-wa kanasii -toki TOP be-sad-PRES when kokyoo -o omoidasu daroo. home-town ACC remember-PRES probably 'Taroo will probably remember his home town when he is sad.'

If we assume with Stump that present tense can refer to non-past times, we predict that (16e) translates as (17), which is a contradiction:

(17) $\exists \mathrm{t}\left[\mathrm{s}^{*} \leq \mathrm{t} \&\right.$ Taroo is sad at $\mathrm{t} \&$ $\mathrm{t}<\mathrm{s}^{*} \&$ Taroo remembers his home town at $\left.\mathrm{t}\right]$

In Japanese, tense morphemes are quite well-behaved in that their semantic contributions are always determined in relation to structurally higher tenses. Temporal adverbial clauses are no exceptions. The right interpretations for the above data are predicted by a simple theory in which a tense in a temporal adverbial clause is in the scope of the tense in the matrix clause. According to this theory, (16a-f) translate as (18a-f): 
(18) a. $\exists \mathrm{t}\left[\mathrm{t}<\mathrm{s}^{*} \&\right.$ Taroo calls Hanako at $\mathrm{t} \& \exists \mathrm{t}^{\prime}\left[\mathrm{t}<\mathrm{t}^{\prime} \&\right.$ Taroo sees Mary at $\left.\left.\mathrm{t}^{\prime}\right]\right]$

b. $\exists \mathrm{t}\left[\mathrm{t}<\mathrm{s}^{*} \&\right.$ Taroo calls Hanako at $\mathrm{t} \& \quad \exists \mathrm{t}^{\prime}\left[\mathrm{t}^{\prime}<\mathrm{t} \&\right.$ Taroo sees Mary at $\left.\left.\mathrm{t}^{\prime}\right]\right]$

c. $\exists \mathrm{t}\left[\mathrm{s}^{*}<\mathrm{t} \&\right.$ Taroo calls Hanako at $\mathrm{t} \& \exists \mathrm{t}^{\prime}\left[\mathrm{t}<\mathrm{t}^{\prime} \&\right.$ Taroo sees Mary at $\left.\left.\mathrm{t}^{\prime}\right]\right]$

d. $\exists \mathrm{t}\left[\mathrm{s}^{*}<\mathrm{t} \&\right.$ Taroo calls Hanako at $\mathrm{t} \& \exists \mathrm{t}^{\prime}\left[\mathrm{t}^{\prime}<\mathrm{t} \&\right.$ Taroo sees Mary at $\left.\left.\mathrm{t}^{\prime}\right]\right]$

e. $\exists \mathrm{t}\left[\mathrm{t}<\mathrm{s}^{*} \&\right.$ Taroo is sad at $\mathrm{t} \&$ Taroo remembers his home town at $\left.\mathrm{t}\right]$

f. $\exists \mathrm{t}\left[\mathrm{s}^{*}<\mathrm{t} \&\right.$ Taroo is sad at $\mathrm{t} \&$ Taroo remembers his home town at $\left.\mathrm{t}\right]$

In the Japanese examples (16a-f), the temporal order between the two clauses is indicated not only by the temporal connective but also by the tense morpheme in the temporal adverbial clause. A past tense morpheme in an adverbial clause indicates that the adverbial clause event (or state) occurs in the past of the matrix clause situation, which harmonizes with what after means. On the other hand, a present tense morpheme in a temporal adverbial clause shows that the episode described in it is simultaneous with (or is subsequent to) the event or state described in the matrix clause, which is equivalent to what when (or before) means. Thus, at least in Japanese, tenses in temporal adverbial clauses behave as if they are in the scope of matrix clause tenses. ${ }^{9}$

On the assumption that it is desirable to find a theory that works for both English and Japanese, I will pursue the hypothesis that my proposal can account for the semantics of English temporal adverbial clauses as well. I will claim that this is in fact the case on condition that the SOT analysis also extends to temporal adverbial clauses in English. One important caveat is that unlike the case of verb complements and relative clauses, the SOT rule must apply to English temporal adverbial clauses. This means that English temporal adverbial clauses must have become tenseless when they are translated into a logical language and that the temporal order between the main clause and the adverbial clause is indicated only by a temporal connective, unlike Japanese temporal adverbial clauses. Let me show how the English examples considered earlier can be re-analyzed by my proposal. Consider (19a-b), cited earlier as (8) and (10a):

(19) a. John visited the Space Needle after he arrived in Seattle.

b. John will call Mary before he visits her.

(19a-b) are analyzed as in (20a-b), respectively:

(20) a. LF: John visited the Space Needle after he $\varnothing$ arrive in Seattle.

1. he $\varnothing$ arrive in Seattle $\Rightarrow \lambda t$ [he arrives in Seattle at $t$ ]

2. after he $\varnothing$ arrive in Seattle [translation + promotion to a generalized quantifier] $\Rightarrow \lambda P_{t} \lambda t^{\prime \prime} \exists t^{\prime}\left[\right.$ he arrive in Seattle at $\left.t^{\prime} \& t^{\prime}<t^{\prime \prime} \& P_{t}\left(t^{\prime \prime}\right)\right]$

3. John visited the Space Needle $\Rightarrow \lambda t^{\prime}\left[t^{\prime}<s^{*} \&\right.$ he arrives in Seattle at $\left.t^{\prime}\right]$

4. John visited the Space Needle after he $\varnothing$ arrive in Seattle $\Rightarrow$ $\lambda \mathrm{t} \exists \mathrm{t}^{\prime}\left[\mathrm{t}^{\prime}<\mathrm{t} \&\right.$ he arrives in Seattle at $\mathrm{t}^{\prime} \&$ $\mathrm{t}<\mathrm{s}^{*} \&$ John visits the Space Needle at $\left.\mathrm{t}\right]$

5. [existential closure] $\exists t \exists t^{\prime}\left[t^{\prime}<t \&\right.$ he arrives in Seattle at $t^{\prime} \&$ $\mathrm{t}<\mathrm{s}^{*} \&$ John visits the Space Needle at $\left.\mathrm{t}\right]$ 
b. LF: John PRES woll call Mary before he $\varnothing$ visit her.

1. he $\varnothing$ visit her $\Rightarrow \lambda \mathrm{t}$ [he visits her at $\mathrm{t}$ ]

2. before he $\varnothing$ visit her [translation + promotion to a generalized quantifier] $\Rightarrow \lambda \mathrm{P}_{\mathrm{t}} \lambda \mathrm{t}^{\prime \prime} \exists \mathrm{t}^{\prime}\left[\right.$ he visits her at $\left.\mathrm{t}^{\prime} \& \mathrm{t}^{\prime \prime}<\mathrm{t}^{\prime} \& \mathrm{P}_{\mathrm{t}}\left(\mathrm{t}^{\prime \prime}\right)\right]$

3. John PRES woll call Mary $\Rightarrow \lambda \mathrm{t}\left[\mathrm{s}^{*}<\mathrm{t} \&\right.$ John calls Mary at $\left.\mathrm{t}\right]$

4. John PRES woll call Mary before he $\varnothing$ visit her $\Rightarrow$ $\lambda \mathrm{t}^{\prime \prime} \exists \mathrm{t}$ 'he visits her at $\mathrm{t}^{\prime} \& \mathrm{t}^{\prime \prime}<\mathrm{t}^{\prime} \& \mathrm{~s}^{*}<\mathrm{t}^{\prime \prime} \&$ John calls Mary at $\left.\mathrm{t}^{\prime \prime}\right]$

5. [existential closure] $\exists t^{\prime \prime} \exists t^{\prime}$ [he visits her at $t^{\prime} \& t^{\prime \prime}<t^{\prime} \& s^{*}<t^{\prime \prime} \&$ John calls Mary at t"]

(19a) is subject to the SOT rule and the LF structure in (20a) results. The temporal connective after requires that his visiting the Space Needle follow John's arriving in Seattle. This gives us the right truth conditions for (19a). The analysis of (19b) proceeds in a similar manner. As mentioned above, the so-called future tense will in the matrix clause analyzes into the present tense morpheme and the future auxiliary woll, and the present tense in the temporal adverbial clause gets deleted under identity with the matrix present tense morpheme. Since the adverbial clause becomes tenseless before it is translated, it simply denotes the set of times at which John visits Mary. The temporal order between the event of John's visiting Mary and the event of his calling her is determined by the temporal connective before. The above translations predict the right truth conditions for (19a-b). I have thus demonstrated that my proposal accounts for the behavior of tenses in temporal adverbial clauses with no co-occurring quantificational adverb.

\section{Temporal Adverbial Clauses and Quantificational Adverbs}

Let us now turn to examples that involve both temporal adverbial clauses and adverbs of quantification. Consider (21a) and its predicate logic rendition (21b):

(21) a. When Mary telephones, Sam is always asleep.

b. $\forall \mathrm{t}[$ Mary telephones at $\mathrm{t} \rightarrow$ Sam is asleep at $\mathrm{t}]$

Imitating the way nominal quantifiers like every and some are dealt with in a Montagovian semantic system, I tentatively translate always as $\lambda P_{t} \lambda Q_{t} \forall t\left[P_{t}(t)\right.$ $\left.\rightarrow Q_{t}(t)\right]$, where $P_{t}$ and $Q_{t}$ are variables over sets of times. The adverbial clause and the main clause translate as temporal abstracts and serve as arguments of always. (22) results from this analysis. This is essentially the same as Stump's (1985: 178) analysis. 10

As mentioned above, one important ingredient of Stump's approach is that the semantic contribution of each tense morpheme is independently specified with respect to the speech time. Let us consider the predictions made by the above translation of always coupled with Stump's assumption about tense interpretation. First, consider (22a-b):

(22) a. When Mary called John, he was always asleep.

b. When Mary calls John, he always will be asleep. 
The two clauses in (22a) both denote a set of past times since they are in the past tense. (22a) translates as (23):

(23) $\forall \mathrm{t}\left[\left[\mathrm{t}<\mathrm{s}^{*}\right.\right.$ \& Mary calls John at $\left.\mathrm{t}\right] \rightarrow[\mathrm{t}<\mathrm{s} *$ \& John is asleep at $\left.\mathrm{t}]\right]$

The semantic contribution of each past tense morpheme is indicated by the clause $t<s^{*}$. The one in the consequent is redundant but is harmless. Thus, (23) correctly captures the interpretation of (22a). (22b) is interesting because it involves an apparent mismatch between the matrix clause tense and the adverbial clause tense. If we go along with Stump's assumption that English temporal adverbial clauses in the present tense refer to non-past intervals, we predict the following: the temporal adverbial clause denotes (24a), and the main clause (24b). This in turn means that $(22 b)$ is true iff $(24 c)$ holds.

(24) a. $\left\{\mathrm{t} \mid \mathrm{s}^{*} \leq \mathrm{t} \&\right.$ Mary calls John at $\left.\mathrm{t}\right\}$

b. $\left\{\mathrm{t} \mid \mathrm{s}^{*}<\mathrm{t} \&\right.$ John is asleep at $\left.\mathrm{t}\right\}$

c. $\forall \mathrm{t}\left[\left[\mathrm{s}^{*} \leq \mathrm{t} \&\right.\right.$ Mary calls John at $\left.\mathrm{t}\right] \rightarrow\left[\mathrm{s}^{*}<\mathrm{t} \&\right.$ John is asleep at $\left.\left.\mathrm{t}\right]\right]$

(24c) has a minor empirical problem in that if Mary calls John at the speech time, the sentence is false regardless of whether John is asleep then. Intuitively, always must quantify over the set of future times at which Mary calls John.

The assumption that the present tense can denote non-past times has a more serious problem with the Japanese example (25):

(25) Taroo-wa kanasii toki, itumo furusato -o omoidasi -ta.

TOP be-sad-PRES when always home-town ACC remember PAST

'Taroo always remembered his home town when he was sad.'

According to Stump's analysis of present tense, the adverbial clause denotes (26a) and the main clause $(26 \mathrm{~b})$ :

(26) a. $\left\{\mathrm{t} \mid \mathrm{Taroo}\right.$ is sad at $\left.\mathrm{t} \& \mathrm{~s}^{*} \leq \mathrm{t}\right\}$

b. $\left\{\mathrm{t} \mid\right.$ Taroo remembers his home town at $\left.\mathrm{t} \& \mathrm{t}<\mathrm{s}^{*}\right\}$

The prediction is that (25) is true iff (26a) is a subset of (26b). However, (26a) and (26b) in fact have no element in common. Thus, (25) is predicted to be a contradictory sentence. This is clearly the wrong prediction.

Examples like (27a-b) are also problematic for Stump's approach:

(27) a. When stressed, Mary always watched TV.

b. On Sundays, John always went to the movies.

It is intuitively clear that in order to arrive at the right truth conditions, the adverbial expressions (i.e., when stressed and on Sundays) must restrict the quantificational force of always. However, they do not take the form of a complete sentence and hence are tenseless. If we assumed that the first argument of always is constructed solely from the information carried by the adverbial expression, (27a) would translate as (28):

(28) $\forall \mathrm{t}\left[[\right.$ Mary is stressed at $\mathrm{t}] \rightarrow\left[\mathrm{t}<\mathrm{s}^{*} \&\right.$ Mary watches TV at $\left.\left.\mathrm{t}\right]\right]$

(28) incorrectly predicts that every time of Mary's being stressed (including such 
times in the future) is located in the past. Stump (1985: 189-90) discusses example (29), which is similar to (27a-b):

(29) Hearing that song, John always will think of Mary.

Stump's analysis of (29) yields the wrong interpretation. The translation (30) is a slightly simplified version of Stump's original translation of (29). 11

(30) $\exists \mathrm{t}\left[\forall \mathrm{t}_{1}\left[\left[\mathrm{x}\right.\right.\right.$ hears that song at $\left.\mathrm{t}_{1}\right] \rightarrow$

[ $\mathrm{t}_{1} \subseteq \mathrm{t} \& \mathrm{~s}^{*}<\mathrm{t}_{1} \&$ John thinks of Mary at $\left.\mathrm{t}_{1}\right]$ ]]

Intuitively, always must quantify only over future times of John's hearing that song. However, (30) requires that always quantify over all times of John's hearing that song, including those that are located earlier than the speech time. Suppose that there will be twenty future events of John's hearing that song, and all of them made John think of Mary. Intuitively, (29) is true in this situation. However, if there is at least one past event of John's hearing that song, the sentence is predicted to be false. This is counter-intuitive. 12 One possible solution is to "import" the future tense meaning (i.e., the clause $s^{*}<t$ ) into the first argument of often'. For example, We should translate (29a) as (31), rather than as (30):

(31) $\forall t_{1}\left[\left[s^{*}<t_{1} \& x\right.\right.$ hears that song at $\left.t_{1}\right] \rightarrow$ John thinks of Mary at $\left.t_{1}\right]$

However, this leaves us with a conceptual problem: why is it that a tense morpheme is an obligatory element in the main clause when a tense interpretation seems to be required in the temporal adverbial expression, which is often tenseless?

Given the above problem, incorporating my SOT approach to tenses at first appears to be no better than the proposal based upon Stump's analysis of tense interpretation. Let us examine (32a) $(=(22 b))$ :

(32) a. When Mary calls John, he always will be asleep.

b. When Mary $\varnothing$ call John, he always will be asleep.

The SOT rule deletes the present tense morpheme in the temporal adverbial clause, and (32b) results. Having no tense morpheme, the temporal adverbial clause translates as $\lambda t$ [Mary calls John at $t$ ]. On the other hand, the main clause translates as $\lambda t\left[s^{*}<t \&\right.$ he is asleep at $\left.t\right]$. Assuming the generalized quantifier analysis of always, (32a) is predicted to be true iff (33a) is a subset of (33b).

(33) a. \{t I Mary calls John at $t\}$

b. $\left\{t \mid s^{*}<t \&\right.$ he is asleep at $\left.t\right\}$

This means that (32a) is true only if Mary never called John in the past. This is empirically incorrect. This problem is caused by the deletion of the present tense in the adverbial clause. As mentioned above, Stump has no problem in this case. He only has a minor problem when before or after is involved.

It seems that my approach to tense interpretation also has a problem with the Japanese example (25), repeated here as (34a). The adverbial clause is interpreted simply as the set of times at which Taroo is sad, and (34a) is predicted to be true iff (34b) is a subset of (34c). 
(34) a. Taroo-wa kanasii toki, itumo furusato -o omoidasi -ta. TOP be-sad-PRES when always home-town ACC remember PAST 'Taroo always remembered his home town when he was sad.'

b. $\{t \mid$ Taroo is sad at $t\}$

c. $\left\{t \mid t<s^{*} \&\right.$ Taroo remembers his home town at $\left.t\right\}$

Unfortunately, this gives us the wrong truth conditions for (34a). The proposal incorrectly predicts that (34a) is true only if Taroo will never be sad in the future. In order for my proposal to work, the adverbial clause must be in the scope of the matrix clause tense. However, under the current proposal, both the adverbial clause and the main clause serve as arguments of a quantificational adverb, and they are scopally independent of each other. The question is how to solve this dilemma. (35) represents the function-argument structure that we so far assumed for examples like (34a):

(35) always' $(\lambda t[\ldots t \ldots])\left(\lambda t^{\prime}\left[\ldots t^{\prime}<s^{*} \& \ldots t^{\prime} \ldots\right]\right)$,

where $\lambda \mathrm{t}[\ldots \mathrm{t} \ldots]$ is the translation of the temporal adverbial clause,

and $\lambda t^{\prime}\left[\ldots t^{\prime}<s^{*} \& \ldots t^{\prime} \ldots\right]$ the translation of the main clause

It turns out that the alleged problems with my proposal are caused by the assumption that the scope of the matrix clause tense is narrower than the adverb of quantification. I will argue in the rest of the paper that this assumption is incorrect. Once we understand that the matrix clause tense has scope over the quantificational adverb, the problems presented above turn out to be pseudoproblems.

\section{A New Proposal}

At this point, let us turn to a different approach to temporal phenomena offered by Discourse Representation Theory (DRT) (Kamp 1981, Kamp and Rohrer 1983, Hinrichs 1981, 1986, Partee 1984, Kamp and Reyle 1993). In DRT, a multi-sentence discourse is mapped to a discourse representation structure (DRS), which then receives a model-theoretical interpretation. Kamp and Reyle (1993) propose an analysis of temporal phenomena within DRT, in which matrix clause tenses always have maximal scope. In particular, they have scope over adverbs of temporal quantification. Kamp and Reyle (1993: 642) discuss (36):

(36) In 1985 Mary always went swimming in the moming.

Kamp and Reyle symbolize (36) as (37a), which receives the same interpretation as the predicate logic formula (37b):

(37) a. $\left[\mathrm{s}^{*}, \mathrm{t}_{\mathrm{t}} \mathrm{t}_{1}, \mid \mathrm{t}<\mathrm{s}^{*}, 1985\left(\mathrm{t}_{1}\right), \mathrm{t}=\mathrm{t}_{1}\left[\left[\mathrm{t}_{2} \mid\right.\right.\right.$ day $\left.\left(\mathrm{t}_{2}\right), \mathrm{t}_{2} \subseteq \mathrm{t}\right]$

every $\mathrm{t}_{2} \rightarrow\left[\mathrm{e}, \mathrm{t}_{3} \mid\right.$ morning of $\left(\mathrm{t}_{2}, \mathrm{t}_{3}\right), \mathrm{e} \subseteq \mathrm{t}_{3}$, e: Mary go swimming]]]

b. $\exists \mathrm{t}\left[\mathrm{t}<\mathrm{s}^{*} \& 1985(\mathrm{t}) \& \forall \mathrm{t}_{2}\left[\left[\right.\right.\right.$ day $\left.\left(\mathrm{t}_{2}\right) \& \mathrm{t}_{2} \subseteq \mathrm{t}\right] \rightarrow$

$\exists e \exists t_{3}\left[t_{3}\right.$ is the morning of $t_{2} \& e \subseteq t_{3} \&$ go-swimming' (e, Mary)]]]

Since DRT's representational language makes use of events and states in addition to times, its translation in predicate logic (37b) employs those expressions as well.

For example, $e \subseteq t_{3}$ reads 'the temporal extension of $e$ is part of $t_{3}$ ' and go- 
swimming' (e, Mary) 'e is an event of Mary's going swimming.' The important idea here is that the past tense morpheme has maximal scope and introduces a past interval that restricts the quantificational force of always. Although this analysis of the matrix clause tense does not seem to be crucial in cases like (36), where the frame adverbial in 1985 restricts the domain of quantification for always to a single interval, Kamp and Reyle's idea can be employed to account for the examples that involve both temporal adverbial clauses and adverbs of quantification.

Let us now discuss the constructions in Japanese and English that are particularly problematic for the proposals considered so far. I will show how (38a), which repeats (27a), is analyzed by a new proposal that combines Kamp and Reyle's idea and mine. By assuming that the past tense in the matrix clause has scope over the adverb of quantification, we derive its LF structure (38b):

(38) a. When stressed, Mary always watched TV.

b. PAST [always [when stressed][Mary watch TV]]

The translation of (38b) is shown in (39):

(39) 1. $P A S T \Rightarrow \lambda P_{t} \lambda t^{\prime} \exists t\left[t<t^{\prime} \& P_{t}(t)\right]$

2. always $\Rightarrow \lambda P_{t} \lambda Q_{t} \lambda t^{\prime} \forall t\left[\left[P_{t}(t) \& t \subseteq t^{\prime}\right] \rightarrow Q_{t}(t)\right]$

3. when stressed $\Rightarrow \lambda t$ [Mary is stressed at $t$ ]

4. Mary watch $\mathrm{TV} \Rightarrow \lambda \mathrm{t}$ [Mary watches $\mathrm{TV}$ at $\mathrm{t}]$

5. [always [when stressed][Mary watches TV]] $\Rightarrow$ $\lambda \mathrm{t}^{\prime} \forall \mathrm{t}\left[\left[\right.\right.$ Mary is stressed at $\left.\mathrm{t} \& \mathrm{t} \subseteq \mathrm{t}^{\prime}\right] \rightarrow$ Mary watches TV at $\left.\mathrm{t}\right]$

6. PAST [always [when stressed][Mary watch TV]] $\Rightarrow$ $\lambda \mathrm{P}_{\mathrm{t}} \lambda \mathrm{t}_{1} \exists \mathrm{t}\left[\mathrm{t}<\mathrm{t}_{1} \& \mathrm{P}_{\mathrm{t}}(\mathrm{t})\right]\left(\lambda \mathrm{t}^{\prime} \forall \mathrm{t}\left[\left[\right.\right.\right.$ Mary is stressed at $\left.\mathrm{t} \& \mathrm{t} \subseteq \mathrm{t}^{\prime}\right] \rightarrow$ Mary watches TV at $t]$ )

7. $\lambda \mathrm{t}_{1} \exists \mathrm{t}^{\prime}\left[\mathrm{t}^{\prime}<\mathrm{t}_{1} \& \forall \mathrm{t}\left[\left[\right.\right.\right.$ Mary is stressed at $\left.\mathrm{t} \& \mathrm{t} \subseteq \mathrm{t}^{\prime}\right] \rightarrow$ Mary watches TV at $t]]$

8. [Truth Definition: A matrix sentence $S$ counts as a true sentence iff $S^{\prime}\left(s^{*}\right)$ is true with respect to the model, where $S^{\prime}$ is the translation of $S$.] $\exists \mathrm{t}^{\prime}\left[\mathrm{t}^{\prime}<\mathrm{s}^{*} \& \forall \mathrm{t}\left[\left[\right.\right.\right.$ Mary is stressed at $\left.\mathrm{t} \& \mathrm{t} \subseteq \mathrm{t}^{\prime}\right] \rightarrow$ Mary watches TV at $\left.\left.\mathrm{t}\right]\right]$

The matrix clause tense has the widest scope and provides a past interval that restricts the domain of quantification for always. As a result, always quantifies over some set of past times at which Mary is stressed. As can be easily verified, the last line provides the right truth conditions for (38a). The same approach can deal adequately with (40a), which involves a temporal adverbial clause. The SOT rule deletes the past tense in the adverbial clause, and the LF structure (40b) is obtained:

(40) a. When Mary telephoned, Sam was always asleep.

b. PAST [always [when Mary $\varnothing$ telephone],[Sam be asleep]]

The translation of $(40 \mathrm{~b})$ is given in (41): 
(41) 1. [always [when Mary $\varnothing$ telephone],[Sam be asleep]] $\Rightarrow$ $\lambda \mathrm{t}^{\prime} \forall \mathrm{t}\left[\left[\right.\right.$ Mary telephones at $\left.\mathrm{t} \& \mathrm{t} \subseteq \mathrm{t}^{\prime}\right] \rightarrow$ Mary is asleep at $\left.\mathrm{t}\right]$

2. PAST [always [when Mary $\varnothing$ telephone],[Sam be asleep]] $\Rightarrow$ $\lambda \mathrm{t}_{1} \exists \mathrm{t}^{\prime}\left[\mathrm{t}^{\prime}<\mathrm{t}_{1} \& \forall \mathrm{t}\left[\left[\right.\right.\right.$ Mary telephones at $\left.\mathrm{t} \& \mathrm{t} \subseteq \mathrm{t}^{\prime}\right] \rightarrow$ Mary is asleep at $\left.\left.\mathrm{t}\right]\right]$

3. [Truth Definition] $\exists \mathrm{t}^{\prime}\left[\mathrm{t}^{\prime}<\mathrm{s}^{*} \& \forall \mathrm{t}\left[\left[\right.\right.\right.$ Mary telephones at $\left.\mathrm{t} \& \mathrm{t} \subseteq \mathrm{t}^{\prime}\right] \rightarrow$ Mary is asleep at $\left.\left.\mathrm{t}\right]\right]$

Since the domain of quantification for always is restricted to past intervals, the problems pointed out above do not occur in this proposal.

Consider now the Japanese example (42) $(=(25)$ and (34a)), in which both a temporal adverbial clause and a quantificational adverb occur:

(42) Taroo-wa kanasii toki, itumo furusato -o omoidasi -ta. TOP be-sad-PRES when always home-town ACC remember PAST 'Taroo always remembered his home town when he was sad.'

Our new proposal produces its LF structure (43a) (given in English) and its translation (43b):

(43) a. PAST [always [Taroo be sad][Taroo remember his home town]]

b. $\exists \mathrm{t}^{\prime}\left[\mathrm{t}^{\prime}<\mathrm{s}^{*} \& \forall \mathrm{t}\left[\left[\mathrm{T}\right.\right.\right.$ aroo is sad at $\left.\mathrm{t} \& \mathrm{t} \subseteq \mathrm{t}^{\prime}\right] \rightarrow$ Taroo remembers his home town at $t]]$

(43b) provides the right interpretation.

Lastly, consider the English example (44a), which was presented earlier as (22b) and also as (32a):

(44) a. When Mary calls John, he always will be asleep.

b. PRES [woll [always[When Mary $\varnothing$ call John], [John be asleep]]]

According to the proposed analysis, (44a) has no tense mismatch. Both the temporal adverbial clause and the matrix clause are morphologically in the present tense. Thus, the SOT rule applies to (44a), and the LF structure (44b) results. The translation of $(44 \mathrm{~b})$ is given in (45):

(45) 1. [always [When Mary $\varnothing$ call John], [John be asleep]] $\Rightarrow$ $\lambda \mathrm{t}^{\prime} \forall \mathrm{t}\left[\left[\right.\right.$ Mary calls John at $\left.\mathrm{t} \& \mathrm{t} \subseteq \mathrm{t}^{\prime}\right] \rightarrow$ John is asleep at $\left.\mathrm{t}\right]$

2. woll $\Rightarrow \lambda \mathrm{P}_{\mathrm{t}} \mathrm{t}_{1} \exists \mathrm{t}\left[\mathrm{t}_{1}<\mathrm{t} \& \mathrm{Pt}_{\mathrm{t}}(\mathrm{t})\right]$

3. [woll [always[When Mary $\varnothing$ call John], [John be asleep]] $\Rightarrow$ $\lambda \mathrm{t}_{1} \exists \mathrm{t}^{\prime}\left[\mathrm{t}_{1}<\mathrm{t}^{\prime} \& \forall \mathrm{t}\left[\left[\right.\right.\right.$ Mary calls John at $\left.\mathrm{t} \& \mathrm{t} \subseteq \mathrm{t}^{\prime}\right] \rightarrow$ John is asleep at $\left.\left.\mathrm{t}\right]\right]$

4. $\mathrm{PRES} \Rightarrow \lambda \mathrm{P}_{\mathrm{t}} \lambda \mathrm{t}\left[\mathrm{P}_{\mathrm{t}}(\mathrm{t})\right]$

5. PRES [woll [always[When Mary $\varnothing$ call John], [John be asleep]]] $\Rightarrow$ $\lambda \mathrm{t}_{1} \exists \mathrm{t}^{\prime}\left[\mathrm{t}_{1}<\mathrm{t}^{\prime} \& \forall \mathrm{t}\left[\left[\right.\right.\right.$ Mary calls John at $\left.\mathrm{t} \& \mathrm{t} \subseteq \mathrm{t}^{\prime}\right] \rightarrow$ John is asleep at $\left.\left.\mathrm{t}\right]\right]$

6. [Truth Definition] $\exists \mathrm{t}^{\prime}\left[\mathrm{s}^{*}<\mathrm{t}^{\prime} \& \forall \mathrm{t}\left[\left[\right.\right.\right.$ Mary calls John at $\left.\mathrm{t} \& \mathrm{t} \subseteq \mathrm{t}^{\prime}\right] \rightarrow$ John is asleep at $\left.\left.\mathrm{t}\right]\right]$

The final line says that there is a future interval such that within this interval, 
whenever Mary calls John, he is asleep. The Japanese sentence that parallels (44a) receives the same account. Unlike Stump, I do not assume that the present tense in English has a non-past interpretation in this type of example. The new proposal also avoids the minor empirical problem with Stump's analysis we discussed above.

The careful reader might have realized that "exporting" the matrix past tense morpheme to the temporal adverbial expression has the same semantic effect as my proposal. However, my approach is more intuitively appealing in that tenses in matrix clauses always have scope over tenses in other clauses. Moreover, when the adverbial that restricts the quantificational force of an adverb of quantification is not a clause, it is odd to assume that it receives a temporal interpretation normally associated with tensed clauses.

\section{Further Issues}

I did not discuss in section 5 examples in which before or after occurs. This is because such examples are known to involve an independent problem noted by Partee (1984: 273). Consider (46a):

(46) a. Before John makes a phone call, he always lights up a cigarette.

b. $\forall \mathrm{t} \forall \mathrm{t}^{\prime}\left[\left[\mathrm{J}\right.\right.$ ohn makes a phone call at $\left.\mathrm{t} \& \mathrm{t}^{\prime}<\mathrm{t}\right] \rightarrow$ John lights up a cigarette at $\left.\mathrm{t}^{\prime}\right]$

c. $\forall \mathrm{t}$ [John makes a phone call at $\mathrm{t} \rightarrow$ $\exists \mathrm{t}^{\prime}\left[\mathrm{t}^{\prime}<\mathrm{t} \&\right.$ John lights up a cigarette at $\left.\left.\mathrm{t}^{\prime}\right]\right]$

Partee notes that if we introduce the time of John's lighting up a cigarette in the antecedent as in (46b), we predict incorrectly the John lights up a cigarette at all times before he makes a phone call. However, if it is introduced in the consequent as in (46c), one event of John's lighting up a cigarette that precedes all occurrences of John's making a phone call suffices to make (46a) true. This is also counter-intuitive. One solution to this problem was suggested by de Swart (1991), which requires a different analysis of temporal connectives than the one assumed in section 5. The proposal made in this paper could be combined with de Swart's analysis to deal with examples like (47a) and (47b) in an empirically satisfactory way:

(47) a. Before John visited Mary, he always called her.

b. After John arrived at his office, he always checked his e-mail.

I will leave this project to another occasion.

\section{Conclusion}

In this paper, I discussed the interaction between tenses, temporal adverbial clauses, and adverbs of quantification. I defended a theory of tense that has the following ingredients. The SOT rule in English applies to temporal adverbial clauses as well as to verb complements and relative clauses. NPs, including relativized ones, are subject to scoping. Otherwise, tenses are in general interpreted as if they are embedded in the scope of structurally higher tenses. When an adverb of quantification and a temporal adverbial clause occur in the same sentence, the main clause tense is understood to have scope over the adverb of quantification and the tense morpheme in the temporal adverbial clause. 
Semantically, this means that the matrix tense serves to restrict the domain of quantification for a quantificational adverb. Although some problems remain, the above proposal offers a natural solution to some of the problems raised in the literature.

\section{Endnotes}

1 A brief remark on the logical notation is in order. I will make various simplifications in this paper. For example, nominal expressions are not fully analyzed and are often given reduced representations. Model-theoretic interpretations of the logical representations are assumed rather than explicitly stated. Furthermore, some empirical details that are irrelevant to the main purpose of this paper are simplified.

2 In a more formal logical language, times can appear as a special argument of predicates. For example, John dies at $t$ can be rendered as $\operatorname{dies}^{\prime}(t, j)$.

3 I assume that the English present tense morpheme must denote the speech time. This is due to its exceptional property clearly exhibited by (i):

(i) John met a man who is holding a book in his hand.

According to my analysis, the relative clause NP has the option of remaining in the scope of the matrix past tense. However, the relative clause tense can only be interpreted as referring to the speech time. This can only be accounted for by stipulating that the English present tense must denote the speech time. This can be executed in several ways. In my earlier work (Ogihara 1989), I stipulated that the English present tense must undergo the SOT rule if the structural condition is met. Thus, in (4a) the present tense in the narrow scope relative clause must be deleted although the SOT rule itself is an optional rule.

4 The default interpretation is a simultaneous interpretation, but an independent interpretation is also available if some appropriate adverbials are supplied as in (i):

(i) Taroo-wa [asoko -de kodomo-no yooni nai-te ir -u otoko]

$$
\text { TOP over there at child as if cry PROG PRES man }
$$

ni kinoo au -ta.

DAT yesterday meet PAST

'Yesterday Taroo met the man who is now crying like a baby over there.'

5 According to the analysis assumed here, the common noun man is not in the scope of the relative clause tense. Thus, strictly speaking, (7b) and (7c) do not entail (7a). This analysis of the temporal interpretation of common nouns may be controversial. See Ogihara (1989) for details.

6 Temporal adverbial clauses do not directly translate as generalized quantifiers of times because the intermediate-level translation as a temporal abstract is needed for those cases that involve an adverb of quantification. See Stump (1985) for details.

7 Smith (1975: 73) points out, however, that cases involving verb phrase deletion sound much better:

(i) John will leave when Mary will. 
I have no explanation for this fact.

8 I assume that the so-called present tense in Japanese is ambiguous between a present tense meaning and a future tense meaning. See Ogihara (1989) for details. 9 When the meaning of the tense and that of the connective do not match, the resulting sentence is uninterpretable:

$$
\begin{aligned}
& \text { \#Taroo wa Hanako-ni au -ta mae -ni denwa-o si-ta. } \\
& \text { TOP DAT meet PAST before at phone ACC do PAST }
\end{aligned}
$$

10 I assume a similar analysis for often and sometimes.

11 The representation given here is a simplified version of Stump's proposal in that I ignore the distinction between stages and individuals assumed by Stump. I also dropped Stump's intensional logic variable M, which accounts for the subtle time gaps between the adverb clause event and the main clause event. I trust that these simplifications do not distort the main claim originally made by Stump.

12 There are at least two more recent proposals that are important for our purposes: Rooth (1985) and de Swart (1991). I cannot discuss them in this paper, but as far as I can see, their proposals have the same problem as Stump's, and the solution that I will put forth in section 5 applies mutatis mutandis to their approaches as well.

\section{References}

Abusch, Dorit. (1988) "Sequence of Tense, Intensionality and Scope", Proceedings of the West Coast Conference on Formal Linguistics 7, 1-14, Stanford Linguistics Association, Stanford University.

Dowty, David. (1979) Word Meaning and Montague Grammar, D. Reidel, Dordrecht.

Hinrichs, Erhard. (1981) Temporale Anaphora im Englischen, Staatsexamen thesis, University of Tübingen.

Hinrichs, Erhard. (1986) "Temporal Anaphora in Discourses of English", Linguistics and Philosophy 9, 63-82.

Hintikka, Jaakko. (1969) "Semantics for Propositional Attitudes", in J. W. Davis (ed.), Philosophical Logic, D. Reidel, Dordrecht, 21-45.

Kamp, Hans. (1981) "A Theory of Truth and Semantic Representation", in J. A. G. Groenendijk, T. M. V. Janssen, and M. B. J. Stockhof (eds.), Formal Methods in the Study of Natural Language, Mathematisch Centrum, Amsterdam, 277-322.

Kamp, Hans and Christian Rohrer. (1983) "Tense in Texts", in R. Bäuerle et al. (eds.), Meaning Use and Interpretation of Language, Walter de Gruyter, Berlin, 250-269.

Kamp, Hans and Uwe Reyle. (1993) From Discourse to Logic, Introduction to Modeltheoretic Semantics of Natural Language, Formal Logic and Discourse Representation Theory, Kluwer, Dordrecht.

May, Robert. (1977) The Grammar of Quantification, Doctoral dissertation, MIT.

Montague, Richard. (1973) "The Proper Treatment of Quantification in Ordinary English", in J. Hintikka, J. Moravcsik, and P. Suppes (eds.), Approaches to Natural Language, D. Reidel, Dordrecht. 
Nakau, Minoru. (1976) "Tense, Aspect, and Modality", in Masayoshi Shibatani (ed.), Syntax and Semantics 5, Japanese Generative Grammar, Academic Press, New York.

Needham, Paul. (1975) Temporal Perspective, Filosofiska Studier 25, Uppsala, Sweden.

Ogihara, Toshiyuki. (1987) "On 'Past Tense' in Japanese," Texas Linguistic Forum 28, Univ. of Texas at Austin, 73-90.

Ogihara, Toshiyuki. (1989) Temporal Reference in English and Japanese. Doctoral dissertation, University of Texas at Austin. [Distributed in 1992 by Indiana University Linguistics Club.]

Ogihara, Toshiyuki. (ms.) "The Semantics of Tense in Embedded Clauses", University of Washington.

Ota, Akira. (1973) "Tense Correlations in English and Japanese", Studies in English Linguistics 2, 108-21.

Partee, Barbara Hall. (1984) "Nominal and Temporal Anaphora", Linguistics and Philosophy 7, 243-286.

Prior, Arthur. (1967) Past, Present, and Future, Clarendon Press, Oxford.

Rooth, Mats. (1985) Association with Focus, Doctoral dissertation, University of Massachusetts at Amherst.

Smith, Carlota. (1975) "The Analysis of Tense in English", Texas Linguistic Forum 1, 71-89.

Stump, Gregory. (1985) The Semantic Variability of Absolute Constructions, Kluwer, Dordrecht.

de Swart, Henriëtte. (1991) Adverbs of quantification: a Generalized Quantifier approach, Doctoral dissertation, Rijksuniversiteit Groningen.

Department of Linguistics, GN-40

University of Washington

Seattle, WA 98195

ogihara@u.washington.edu 